\title{
In-vitro diagnosis of single and poly microbial species targeted for diabetic foot infection using e-nose technology
}

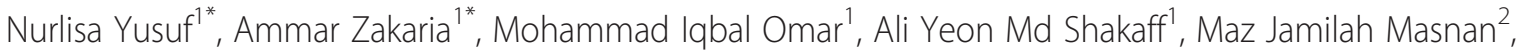 \\ Latifah Munirah Kamarudin', Norasmadi Abdul Rahim', Nur Zawatil Isqi Zakaria', Azian Azamimi Abdullah³, \\ Amizah Othman ${ }^{4}$ and Mohd Sadek Yasin ${ }^{4}$
}

\begin{abstract}
Background: Effective management of patients with diabetic foot infection is a crucial concern. A delay in prescribing appropriate antimicrobial agent can lead to amputation or life threatening complications. Thus, this electronic nose (e-nose) technique will provide a diagnostic tool that will allow for rapid and accurate identification of a pathogen.

Results: This study investigates the performance of e-nose technique performing direct measurement of static headspace with algorithm and data interpretations which was validated by Headspace SPME-GC-MS, to determine the causative bacteria responsible for diabetic foot infection. The study was proposed to complement the wound swabbing method for bacterial culture and to serve as a rapid screening tool for bacteria species identification. The investigation focused on both single and poly microbial subjected to different agar media cultures. A multi-class technique was applied including statistical approaches such as Support Vector Machine (SVM), K Nearest Neighbor $(K N N)$, Linear Discriminant Analysis (LDA) as well as neural networks called Probability Neural Network (PNN). Most of classifiers successfully identified poly and single microbial species with up to $90 \%$ accuracy.

Conclusions: The results obtained from this study showed that the e-nose was able to identify and differentiate between poly and single microbial species comparable to the conventional clinical technique. It also indicates that even though poly and single bacterial species in different agar solution emit different headspace volatiles, they can still be discriminated and identified using multivariate techniques.
\end{abstract}

\section{Background}

Clinically, the microbiology of diabetic foot infection is very unique because it involves either Gram-positive, Gramnegative aerobic, or anaerobic bacteria [1]; whether caused by single or combination of bacteria (poly microbial) infection [2-4]. Single bacteria are the only one bacterial species isolated from multiple bacterial species on debridement of wound. Poly microbial species is the mixing of bacteria species that exist on wound infection. Usually, moderate to severe soft tissue diabetic foot infections are poly microbial containing species such as $P$. aeruginosa, $S$. aureus and group of Enterococci. It usually occurs when the patients

\footnotetext{
* Correspondence: nurlisayusuf@gmail.com; ammarzakaria@unimap.edu.my ${ }^{1}$ Centre of Excellence for Advanced Sensor Technology, Universiti Malaysia Perlis, Perlis, Malaysia

Full list of author information is available at the end of the article
}

received empiric antibiotic therapy [5]. Therefore, selecting appropriate antibiotics for the treatment of diabetic foot infection is crucial. It requires careful consideration in terms of severity of infection, duration of wounds and previous antibiotic exposure [5-7]. Although, there is no data to suggest that speeding the diagnosis of diabetic foot infections by 2 to 3 days will improve patient outcomes, nevertheless, the proposed e-nose technology can also improve patient care by improving or reducing drug resistance to infection and more economical since it allows the use of narrow spectrum antibiotics $[5,8,9]$.

In today's clinical practice, diabetic foot infection is diagnosed and monitored through many techniques such as ulcer swabs, curettage of the ulcer base, and needle aspiration after normal saline injection [10-12] to determine the appropriate antibiotics treatment. Other techniques, including tissue biopsy obtained at the bedside or by

\section{Biomed Central}

(c) 2015 Yusuf et al.; licensee BioMed Central. This is an Open Access article distributed under the terms of the Creative Commons Attribution License (http://creativecommons.org/licenses/by/4.0), which permits unrestricted use, distribution, and reproduction in any medium, provided the original work is properly credited. The Creative Commons Public Domain Dedication waiver (http://creativecommons.org/publicdomain/zero/1.0/) applies to the data made available in this article, unless otherwise stated. 
resection at the time of surgery $[11,13]$, may pose a risk to the patients since they involve surgical procedures and need appropriate care. Although these tests have been internationally standardized and are generally considered to be reliable, results still take 2 or 3 days. This constraint is due to the need to grow samples in media culture for at least 48 to 72 hours in order to identify bacteria species.

The use of an e-nose, such as the Cyranose320 to identify bacteria species may outperform conventional methods and address current limitations by providing a faster diagnosis. As a comparison, a chromatography technique that relies on a total ion chromatogram (TIC) may not be sufficient as volatile peaks can overlap [14-16]. However, GCMS commonly applied for similar methods and mass separation can resolve peaks that are not separated by chromatography alone.

Alternatively, E-nose configured on an array of 32 different mixtures with conducting carbon black polymer sensors on a silicon substrate, was believed can be used to detect even the slightest difference in headspace or complex volatiles organic compounds (VOCs) emitted by the different pathogenic microorganisms [17-19]. As such, this non-invasive method may be promising for rapid and accurate detection. It can also prevent complications from a procedure, such as infection and contamination.

Several articles have reviewed clinical applications whereby e-nose technology was applied to non-invasive monitoring of patients [20] in various applications such as in clinical microbiology and for rapid diagnosis of infection from biological samples [18]. Moreover, there were at least 12 reported findings on the ability of an e-nose to identify and discriminate single bacterial species in a closed-loop system [19,21-31]. Previous studies have shown the ability and the robustness of an e-nose to detect the single strain of bacteria on blood culture medium [32,33], and hence opens the way toward making the e-nose applicable in further investigations by direct sniff to the samples [34-39]. Single-strain bacteria are accompanied by or produce characteristic odours often known as a surrogate parameter, and recognition of these odours can provide diagnostic clues, which in turn may aid in planning for early appropriate treatment.

There were many other analytical techniques that have been used for identification of VOCs emitted from bacterial such as solid phase micro extraction-MS (SPME-GCMS) $[40,41]$, proton transfer reaction-MS (PTR-MS) [42], GC with a flame-ionization detector (GC-FID) [13], selected ion flow tube-MS (SIFT-MS) [43], secondary electrospray ionization mass spectrometry (SESI-MS) [44], matrix-assisted laser desorption/ionization time-of-flight mass spectrometry (MALDI-TOF-MS) [45]. Novel basic odour detection was developed and targeted for poly and single microbial bacteria using direct injection of a static head space and in combination with multi-class odour recognition for robust detection of bacterial species on different agar mediums.

In this study, the SPME-GC-MS was chosen to determine the VOCs result since combination of both SPME and GCMS is very popular. SPME uses a polymer-coated fiber to concentrate volatile and semi-volatile organics in one extraction step [46,47]. Gas chromatography- mass spectrometry (GC-MS) is a method that combines the features of gas-liquid chromatography $(\mathrm{GC})$ and mass spectrometry (MS) to identify different kind of substances within a test sample [48]. The key marker volatiles were detected and the volatile compounds emitted from wounds, where bacteria can often be found, verified the possibility of early recognition involved in infection using the SPME technique combined with gas chromatography-mass spectrometry (GC-MS).

To the best of the author's knowledge, this research paper presents a novel work on the identification of both poly and single bacterial subjected to different agar medium using e-nose. Poly microbial infections of diabetic foot patients have not been well reported and documented as the research in this area is quite challenging. Thus, the significance of this experiment and the potential use of this application in a clinical setting are discussed.

\section{Methods}

\section{Media culture preparation}

Blood agar medium was prepared using a 20 g Tryptic Soy Blood Agar Base (TSBA) in $500 \mathrm{~mL}$ distilled water. The medium was then sterilized at $121^{\circ} \mathrm{C}$ and $225 \mathrm{kPa}$ for 15 minutes and cooled to room temperature. After that, $25 \mathrm{~mL}$ of sterile defibrinated blood was placed in the medium and stored at $4^{\circ} \mathrm{C}$.

The same procedure was also applied to the MacConkey agar using $25 \mathrm{~g}$ powdered MacConkey in $500 \mathrm{~mL}$ of distilled water. The medium was then heated with frequent agitation and boiled for one minute to completely dissolve. After the medium was autoclaved at $121^{\circ} \mathrm{C}$ for 15 minutes, the prepared media may turn to dark pink and trace to slightly hazy.

The Mueller Hinton agar was prepared by suspending $19 \mathrm{~g}$ of the medium in $500 \mathrm{~mL}$ of purified water. The medium was heated with frequent agitation and left to boil for one minute to completely dissolve. After the medium was autoclaved at $121^{\circ} \mathrm{C}$ for 15 minutes, it appears as hazy and light to medium yellow when cooled to room temperature.

\section{Bacteria isolation}

Bacterial isolates obtained from the samples debridement of diabetic foot wound (wild-type bacteria) and American Type Culture Collection (ATCC) standard bacterial was prepared as shown in Table 1. Informed consent was 
Table 1 Single and poly microbial species culture on different medium

\begin{tabular}{|c|c|c|c|}
\hline \multirow[b]{2}{*}{ Organism } & \multicolumn{3}{|c|}{$\begin{array}{l}\text { Total no. of data analysis } \\
\text { collected by e-nose }\end{array}$} \\
\hline & $\begin{array}{l}\text { Blood } \\
\text { agar }\end{array}$ & $\begin{array}{l}\text { Mueller } \\
\text { Hinton }\end{array}$ & MacConkey \\
\hline \multicolumn{4}{|l|}{ Gram positive aerobes } \\
\hline S. aureus ATCC 29213 & 750 & 750 & - \\
\hline S. aureus* & 500 & 500 & - \\
\hline \multicolumn{4}{|l|}{ Gram negative aerobes } \\
\hline E. coli ATCC 35218 & 750 & 750 & 750 \\
\hline E. coli* & 500 & 500 & 500 \\
\hline P. aeruginosa ATCC 27853 & 750 & 750 & 750 \\
\hline$P$. aeruginosa* & 500 & 500 & 500 \\
\hline \multicolumn{4}{|l|}{ Mix gram negative aerobes } \\
\hline E. coli* $+P$. aeruginosa* & 350 & 350 & 350 \\
\hline \multicolumn{4}{|c|}{ Mix gram positive and negative aerobes } \\
\hline E. coli* + S. aureus* & 350 & 350 & - \\
\hline S. aureus* $+P$. aeruginosa* & 350 & 350 & - \\
\hline
\end{tabular}

*Isolated from debridement of diabetic foot wound (wild-type bacteria).

obtained from all patients. This method has been granted approval by the University Research Ethics Committee, Universiti Malaysia Perlis to diagnose of single and poly microbial species targeted for diabetic foot infection using e-nose technology. ATCC bacteria are a commercially available bacterium that is used as a standard reference in research. The isolation of bacteria was divided based on gram positive and negative of bacteria strains. Each of the samples was prepared in five plate culture with three different mediums. The total number of data analysis represents the five times repeated measurements of data collected by using the e-nose. The bacterial suspension solution was adjusted to a turbidity of a standard Mac Farland 1.0 (3 $\times$ $10^{8} \mathrm{cfu} / \mathrm{mL}$ ) in a $\mathrm{NaCl}$ solution and then subculture on three different media based on the gram strain of the bacteria. The bacteria were then incubated at $37^{\circ} \mathrm{C}$ for 24 hours before analysis.

\section{E-nose and odour sniffing setup}

The human olfactory system (sense of smell) is a very complex process and responds to certain volatile chemicals that are thought to be important in the detection of irritants and chemically reactive species [17]. Cyranose 320 was selected as an effective instrument that "electronically" mimics the human olfaction system. It was developed as a simplified model of the human olfactory system and was designed to detect and discriminate different complex odours based on a sensor-array concept.

This sensor array consists of broadly tuned (non-specific) and highly selective sensors that are coated with a variety of odour-sensitive absorbent materials. The array combinations together with the odour sniffing setup allow the e-nose to be tuned for a specific application, for example to detect slight changes in an odour profile. The e-nose setup is shown in Figure 1.

\section{Sampling procedure and detection system}

The sampling procedure is started after bacteria were incubated for 24 hours. The investigation was performed on both bacteria (wild-type and ATCC standard) in different nutrient medium, incubated for at least 24 hours to project headspace variability, which may be emitted by the bacterial infection of the patients. A Cyranose320 e-nose system was used to sniff all the samples by transferring the headspace of target samples to the sensors without altering its composition and properties. The target medium agar was inserted in a closed container and the odour sniffing started immediately. This procedure was implemented in such a way as to ensure consistency in e-nose performance on immediate sniffing (in-vivo) of the patient's wound at the clinical stage later. Table 2 shows the measurement parameters for the Cyranose 320.

The analyses result from the use of the e-nose was compared to the results with SPME-Gas Chromatography Mass Spectrometry (SPME-GCMS) to validate the obtained data. Conventional multivariate analysis such as LDA is shown to work effectively with a lower number in

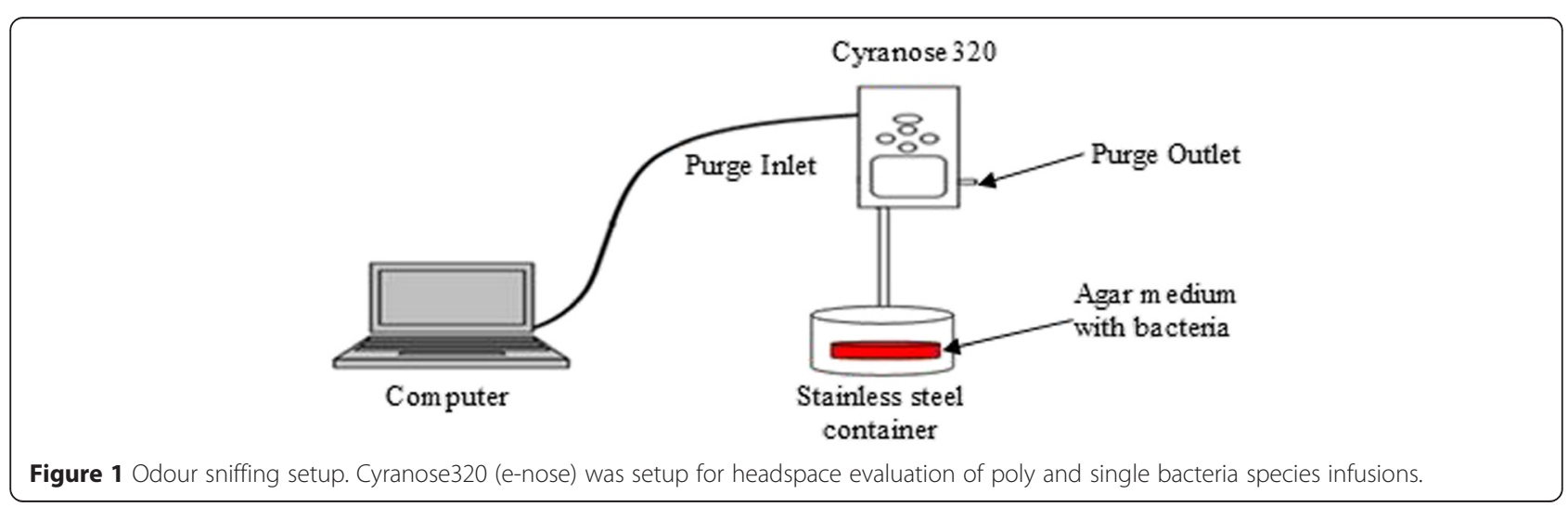


Table 2 The parameter setting for poly and single bacteria assessment

\begin{tabular}{lll}
\hline Cycle & Time (s) & Pump speed \\
\hline Baseline purge & 10 & $120 \mathrm{~mL} / \mathrm{min}$ \\
Sample draw & 60 & $120 \mathrm{~mL} / \mathrm{min}$ \\
Idle time & 3 & - \\
Air intake purges & 40 & $160 \mathrm{~mL} / \mathrm{min}$ \\
\hline
\end{tabular}

class variability. In order to ensure robustness, e-nose data which comprises of high number of class variability was then subjected to different classifiers such as KNN, SVM, and PNN. A hybrid LDA-Classifier was introduced to enhance prediction capability and the performance was compared with classical neural network and statistical methods. These multi-class classification techniques applied in this study was aimed to determine the best classifier to achieve the research objectives.

\section{SPME and GC-MS setting}

A method based on the use of headspace, solid phase micro extraction (SPME), and GCMS was developed to determine the VOCs produced by a single or poly microbial infection extract from patients. The SPME technique was applied using a fused silica-fiber coated on the surface with a film of an immobilized stationery phase that is connected to the plunger of a modified GC syringe and moves inside the needle. The needle made by CAR/PDMS (Supelco-57320-U, Bellefonte, PA, USA) was used in this study to extract the volatile emitted from the bacteria. Then, the needle which has been exposed to the sample headspace for 10 minutes is injected into the manual injector port of a gas chromatograph system.

\section{SPME-GC setting}

An SPME fiber (75 lm Carboxen-PDMS; Supelco, Inc., Bellefonte, PA, USA) was exposed to the sample headspace for 10 minute. The Volatile Organic Compound (VOC) was desorbed by inserting the SPME fiber into a GC injector (injector temperature $230^{\circ} \mathrm{C}$ ) in split less mode connected with a fused-silica GC column (Elite 5MS, $30 \mathrm{~m}, 0.25 \mathrm{~mm}$ ID, $0.25 \mu \mathrm{m}$ film thickness) (Perkin Elmer, Shelton, USA) for 10 minute. The initial temperature of the $\mathrm{GC}$ was set at $70^{\circ} \mathrm{C}$ for $0.5 \mathrm{~min}$, and then the oven temperature was increased at a rate of $20^{\circ} \mathrm{C} / \mathrm{min}$ until it reaches $250^{\circ} \mathrm{C}$ which remained for another $1 \mathrm{~min}$. The detector temperature was set at $250^{\circ} \mathrm{C}$.

\section{GC-MS setting}

For GC-MS analysis, a GC (Clarus680) coupled with a mass spectrometry (Clarus600T, Perkin Elmer, Shelton, USA) was used. The GC operating conditions (temperature and time) were the same as described above. The mass spectrometer was operated in the electron-ionization (EI) mode at an ionization voltage of $70 \mathrm{eV}$.

In order to support the findings of this research, output from GC-MS were also analysed using LDA, KNN, SVM and PNN. Usually GC-MS provides information on specific analytes of interest (selective ion monitoring (SIM) and mass spectra data (SIM and total ion current (TIC). In this research, TIC data was used as input for the classifier. TIC is merely the sum at each time point of every massto-charge ratio $(\mathrm{m} / \mathrm{z})$ value across a mass spectrum [14].

\section{Data analysis and odour recognition}

A surface plot was used to visualize the signal response from the e-nose in a sensor array configuration using the standard toolbox "surfc" functions of MATLAB R2013a to generate graphical plots of all 32 sensors during sniffing. This scientific software is normally used for signal processing [49]. The surfc () function was used to view mathematical functions over a rectangular region and to create colored parametric surfaces specified by normalized values of the sensor responses, sensor number, and the number of gathered data points as shown in Figure 2.

The response pattern of the sensor array is known as a 'smell print' and different bacteria may exhibit different smell print patterns as shown in Figure 2. For instance, sensor 5 is the most sensitive (emitting the highest response) compared to other sensors towards the volatile odour produced by E. coli bacteria. Both sensor 2 and sensor 32 showed the lowest response and may be less sensitive to volatile compounds produced by bacteria.

To ensure the consistency and the robustness of the enose, the dataset was also subjected to different classifiers such as KNN, SVM, and PNN. The performance of each classifier is discussed and compared. The Wilks' Lambda statistical test was carried out to evaluate the statistical significant of all 32 independent conducting polymer sensors by comparing means score of 7 different groups samples, simultaneously. A multi-class odour classification model was later proposed to evaluate the robustness of an e-nose system in classifying unknown single and poly microbial samples.

\section{Feature extraction and dimension reduction}

In this experiment, the steady-state response of each sensor during the sniffing phase was used as a feature extraction. The sensor response was determined by obtaining the difference in values between the ends of the sampling values with the baseline values, which can be denoted as feature extraction. This baseline correction is required to remove a 'drifting effect'.

Principal Component Analysis which is an exploratory data analysis was used to extract the most influential sensors based on the highest principal component. Later, the dataset is fed through a linear classifier known as linear 


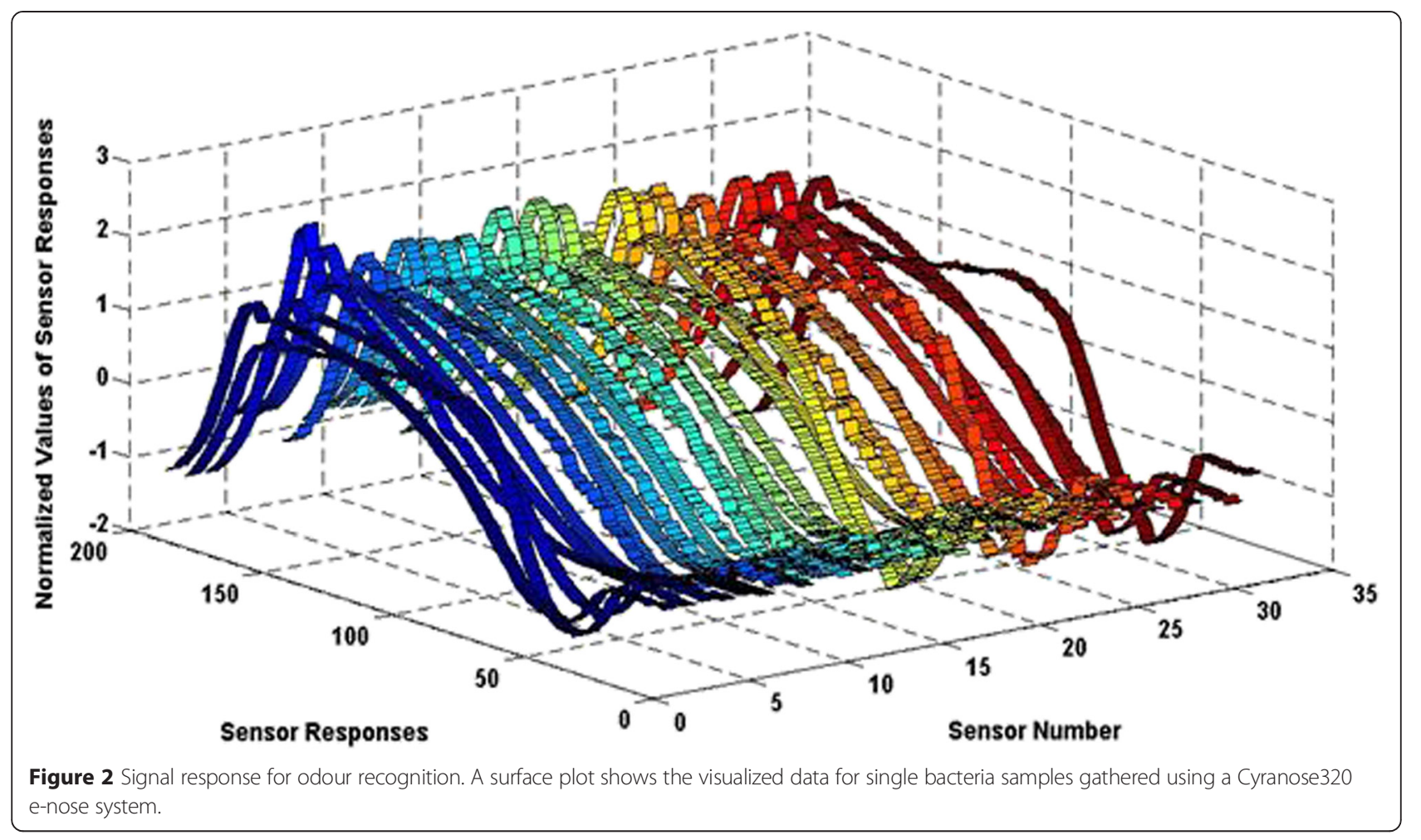

discrimination analysis (LDA) to quantify the discrimination performance of the e-nose. LDA was selected to reduce high-dimensionality data into a much lower dimension and to maximize class separability for bacterial identification [50].

\section{Results}

\section{E-nose results}

The preliminary work was focused on the investigation of volatiles released by a single bacterial species. This also included one-to-one comparison between a wild-type strain and standard ATCC bacteria combined in a blood agar medium. Three different species of bacteria namely, $E$. coli, S. aureus, and P. aeruginosa obtained from ATCC standard were cultured and the volatiles released were measured after an incubation process of 24 hours at $37^{\circ} \mathrm{C}$. Figure 3 shows the results obtained by supervised LDA. The most striking finding was a clear separation between all three different bacteria when LDA was applied.

The result shows that each bacteria species does emit a distinct smell including the blind test that includes wildtype bacteria. Moreover, the blind test samples matched closely with the distribution of the different groups of bacteria in the training data. Both the wild-type strain and ATCC standard bacteria of the same species are clustered in the same group, showing that they emit the same volatiles. Distinct separations between group samples were observed even when the groupings of different bacteria were close to each other. This proves that the e-nose was able to discriminate different volatiles emitted from ATCC and wild-type bacteria.

Further studies was conducted to extend the capability of e-nose to identify more groups of different bacteria categorize under single and poly microbial species within different mediums. Single and poly microbial species as described in the background are investigated and classified using LDA, PNN, KNN and SVM. Due to the limited ratio of the classification diagram and unclear classification plot, the analysis was carried out for both groups of bacteria. However, to clearly show the classification result, one of the diagrams is illustrated in Figure 4.

Figure 4 shows the classification of single bacteria that has been separated into their groups. While Figure 5 shows the overall classification result of both groups of bacteria.

Figure 5 shows the two groups of single and poly microbial species that were successfully classified. For different types of single and poly microbial species dataset, eighteen groups $(\mathrm{G}=18)$ were involved with 32 features $(p=32)$ of the e-nose. The number of useful discriminant functions that can separate the bacteria species by different mediums is the minimum of (G-1) or $p$, and in this case it is the minimum of 17 and 32, that is 17 . In this case, a maximum of 17 useful discriminant functions (DF) can be applied to separate the bacteria species. However, for display purposes only the highest discriminant functions are considered to show the actual classification among 18 different groups of 


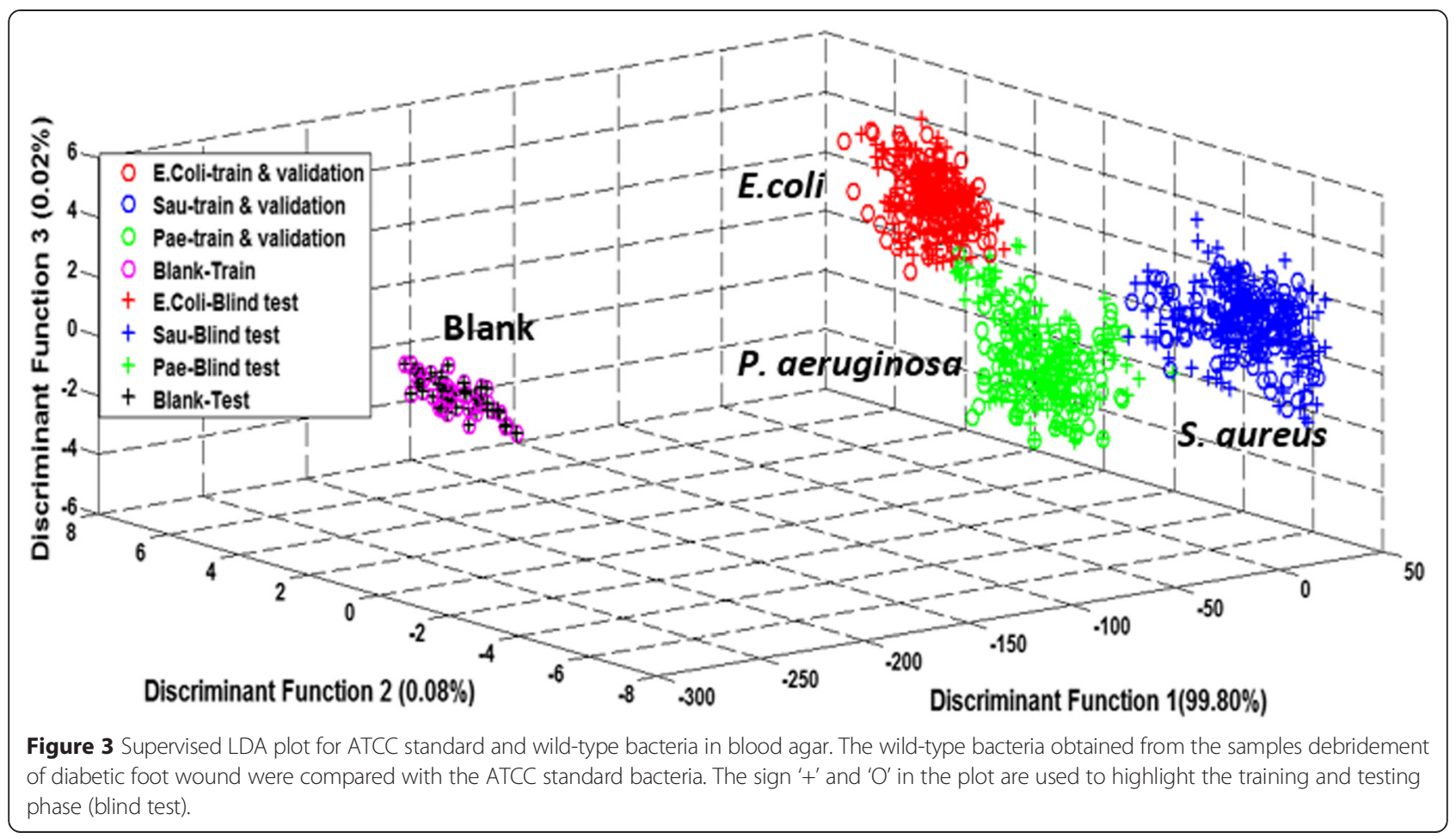

bacteria. Among the highest discriminant function accounted for display are $87.4 \%$ for DF1 and $12.6 \%$ for DF2.

On the other hand, the Wilks' lambda test shows that, there is a statistically significant relationship between the independent variables and the group samples whereby the $p$-value of Discriminant Function 1 through 5 is less than 0.001 as shown in Table 3. The Discriminant Function 6 was statistically less significant as both $\mathrm{p}<0.003$ and Wilks' Lambda value were high. Only the first 3 Discriminant Function was used in the latter analysis.
Evaluation and classification performance

A hybrid LDA-Neural Network classifier was introduced to enhance prediction of unknown sample. Table 4 shows the multi-class classification accuracy of single and poly microbial species when different sets of features are subjected to different classifiers. In order to estimate the performance of the classifier, we adopted the common "leave-one-out" cross validation technique to train and test the remaining samples which were not used during the cross validation process.

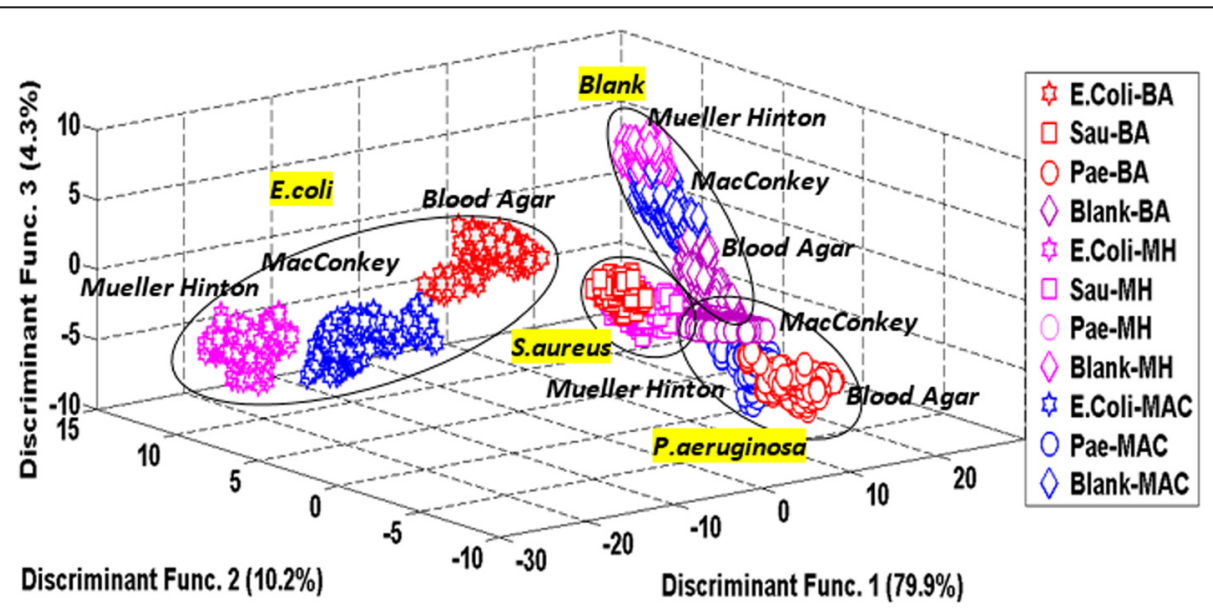

Figure $4 \mathrm{LDA}$ plot of single bacteria species in three different mediums. This diagram is to show the clear vision of one group of single bacteria in three different mediums (blood agar, Mueller Hinton \& MacConkey). 


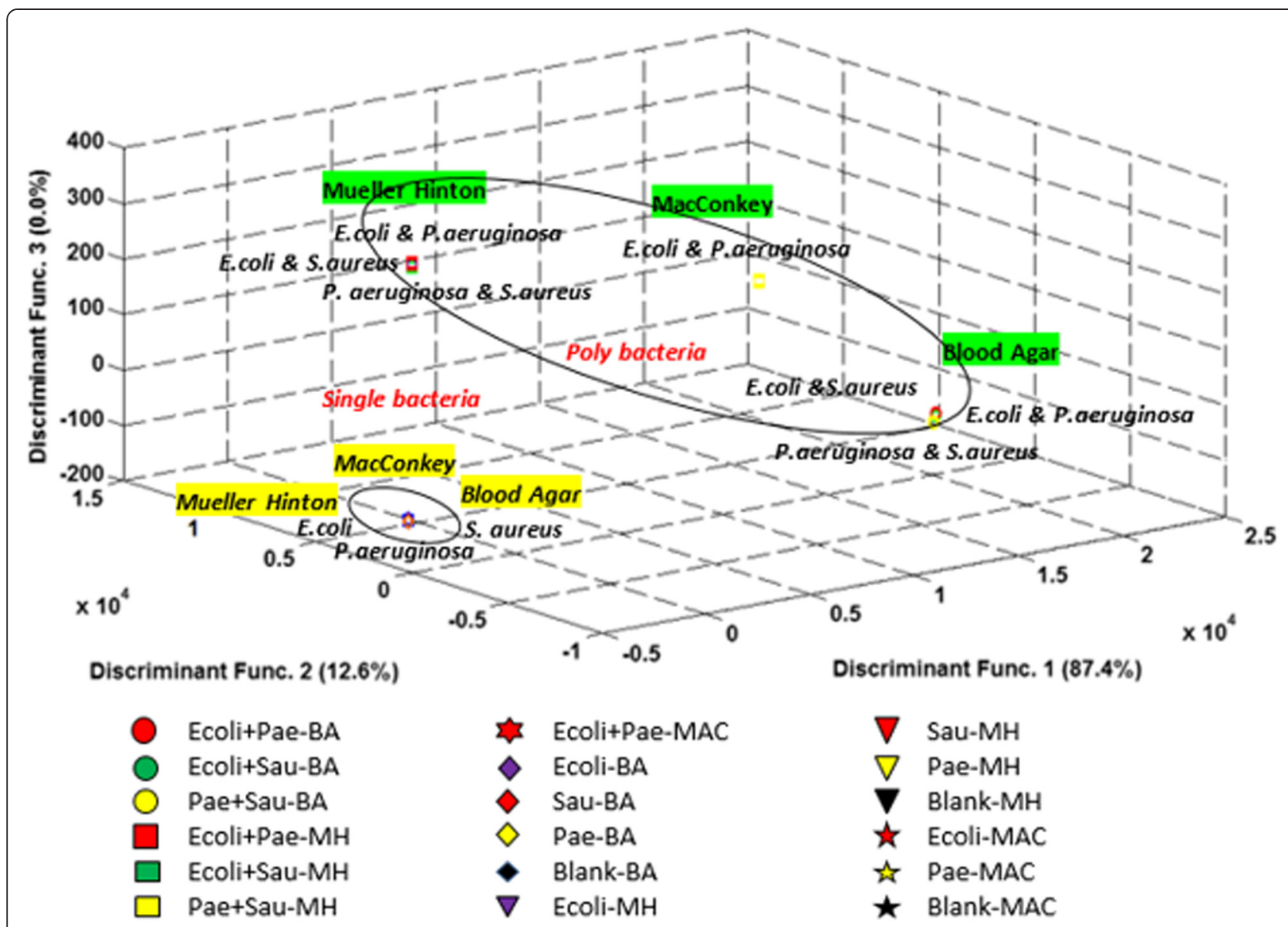

Figure $\mathbf{5}$ LDA plot of single and poly microbial species in three different media. This combination of single and poly microbial in different media is to study the effectiveness of e-nose to classify the bacteria in a different group region.

The results show that almost all classifiers performances in these three different media (blood agar, Mueller Hinton and MacConkey) were achieved up to $89 \%$ accuracy. The blood agar sample was achieved $100 \%$ accuracy, using feature extraction and without feature extraction of the LDA, which indicates an excellent result compared with Mueller Hinton and MacConkey medium. While for PNN and SVM classifiers, using raw data, was not able to achieve higher classification of mixed media data samples. However, using data extracted from a discriminant function of LDA, performance of $96 \%$ accuracy was achieved. The

Table 3 The statistical significance classifiers using Wilks' Lambda

\begin{tabular}{lllll}
\hline Test of function(s) & Wilks' Lambda & Chi-square & df & Sig. \\
\hline 1 through 6 & 0.000 & 19972.418 & 54 & 0.000 \\
2 through 6 & 0.025 & 6706.844 & 40 & 0.000 \\
3 through 6 & 0.180 & 3115.957 & 28 & 0.000 \\
4 through 6 & 0.444 & 1477.723 & 18 & 0.000 \\
5 through 6 & 0.760 & 499.888 & 10 & 0.000 \\
6 & 0.991 & 15.784 & 4 & 0.003 \\
\hline
\end{tabular}

hybrid LDA-KNN achieves highest classification accuracy in mixed media culture. Despite of some inconsistency that were observed in the classification bacteria species of mixed media, the e-nose is still a promising tool for in-situ identification of bacterial infection. Since the highest accuracies obtained for information extracted using LDA, so those data were applied to show the sensitivity and specificity for each bacteria species in mixed media as illustrated in Table 5.

Table 5 represents the sensitivity and specificity for different classifier for each of the bacteria species in mixed media culture. From the perspective of specificity, generally it can be concluded that all the classifiers are good at specifying the different bacteria species in different media culture with their actual group. However, the classifiers' sensitivity is inconsistent where some of the bacteria species using LDA, PNN, KNN and SVM were concerned, was unable to detect some of the bacteria species with particular mediums into the correct groups. Although the performance of KNN classifier achieved the highest accuracies compared to other classifier, 
Table 4 Classification accuracy of both single and poly microbial species in three different mediums using different classifier

\begin{tabular}{|c|c|c|c|c|c|c|c|c|}
\hline \multirow[b]{2}{*}{ Classifiers } & \multicolumn{2}{|c|}{ Blood agar (1,750 data) } & \multicolumn{2}{|c|}{ Mueller Hinton ( 1,750 data) } & \multicolumn{2}{|c|}{ Mac Conkey (1,000 data) } & \multicolumn{2}{|c|}{${ }^{* *}$ Mixed media (4,500 data) } \\
\hline & $\begin{array}{l}\text { Train \& validation } \\
\text { (733 data) }\end{array}$ & $\begin{array}{l}\text { Test } \\
\text { (1017 data) }\end{array}$ & $\begin{array}{l}\text { Train \& validation } \\
\text { (733 data) }\end{array}$ & $\begin{array}{l}\text { Test } \\
\text { (1017 data) }\end{array}$ & $\begin{array}{l}\text { Train \& validation } \\
\text { (399 data) }\end{array}$ & $\begin{array}{l}\text { Test } \\
\text { (601 data) }\end{array}$ & $\begin{array}{l}\text { Train \& validation } \\
\text { (1792 data) }\end{array}$ & $\begin{array}{l}\text { Test } \\
\text { ( } 2708 \text { data) }\end{array}$ \\
\hline LDA & $100 \%$ & $100 \%$ & $99.7 \%$ & $98.7 \%$ & $100 \%$ & $100 \%$ & $95.9 \%$ & $94.7 \%$ \\
\hline PNN & $100 \%$ & $100 \%$ & $100 \%$ & $89.7 \%$ & $98.7 \%$ & $98.2 \%$ & $65.2 \%$ & $63.3 \%$ \\
\hline KNN & $100 \%$ & $100 \%$ & $97.0 \%$ & $95.4 \%$ & $100 \%$ & $100 \%$ & $99.9 \%$ & $99.2 \%$ \\
\hline SVM & $100 \%$ & $100 \%$ & $100 \%$ & $100 \%$ & $100 \%$ & $100 \%$ & $67.3 \%$ & $65 \%$ \\
\hline *PNN & $100 \%$ & $100 \%$ & $100 \%$ & $96.3 \%$ & $100 \%$ & $100 \%$ & $99.2 \%$ & $96.8 \%$ \\
\hline *KNN & $100 \%$ & $100 \%$ & $100 \%$ & $100 \%$ & $100 \%$ & $100 \%$ & $99.9 \%$ & $99.6 \%$ \\
\hline *SVM & $100 \%$ & $100 \%$ & $100 \%$ & $100 \%$ & $100 \%$ & $100 \%$ & $98.9 \%$ & $98.7 \%$ \\
\hline
\end{tabular}

*Data was extracted from a discriminant function of LDA and subjected to classifier input.

**Combination of three media (blood agar, Mueller Hinton \& MacConkey), p value $<0.001$.

refer Table 4, this classifier has low sensitivity to differentiate $S$. aureus bacteria in blood agar and Mueller Hinton media.

\section{Headspace SPME-GCMS results}

The total ion chromatogram (TIC) data of a single and poly microbial profile from headspace-GC-MS is illustrated as in Figures 6 and 7.
Every peak obtained was identified by matching sample mass spectrum with those of the National Institute of Standards and Technology (NIST) MS spectral library for peaks presented in the chromatograms. It has been observed that the biomarkers from 'TIC peaks' for single bacteria species can be extracted and used for classification. The TIC peaks clearly show the VOCs produced from that particular bacteria. Unfortunately for poly microbial species in Figure 7, the bio-marker

Table 5 Sensitivity and specificity of both single and poly microbial species in mixed media using different classifier

\begin{tabular}{|c|c|c|c|c|c|c|c|c|c|}
\hline \multirow{3}{*}{$\begin{array}{l}\text { Mixed } \\
\text { media } \\
\text { culture }\end{array}$} & \multirow{3}{*}{$\begin{array}{l}\text { Bacteria } \\
\text { species }\end{array}$} & \multicolumn{8}{|l|}{ Classifiers } \\
\hline & & \multicolumn{2}{|l|}{ LDA \% } & \multicolumn{2}{|l|}{ PNN \% } & \multicolumn{2}{|l|}{ KNN \% } & \multicolumn{2}{|l|}{ SVM \% } \\
\hline & & Sensitivity & Specificity & Sensitivity & Specificity & Sensitivity & Specificity & Sensitivity & Specificity \\
\hline \multirow{7}{*}{$\mathrm{BA}$} & Ecoli & 100 & 99.65 & 100 & 100 & 100 & 100 & 100 & 100 \\
\hline & Sau & 83.11 & 98.44 & 76.19 & 98.01 & 74.84 & 98.16 & 72.44 & 100 \\
\hline & Pae & 98.72 & 99.96 & 100 & 100 & 100 & 100 & 87.08 & 100 \\
\hline & Blank & 96.48 & 99.30 & 100 & 100 & 100 & 100 & 70.14 & 100 \\
\hline & Ecoli + Pae & 100 & 100 & 100 & 100 & 100 & 100 & 85.88 & 100 \\
\hline & Ecoli + Sau & 100 & 100 & 100 & 100 & 100 & 100 & 100 & 99.07 \\
\hline & $\mathrm{Pae}+\mathrm{Sau}$ & 100 & 100 & 100 & 100 & 100 & 100 & 100 & 100 \\
\hline \multirow{7}{*}{$\mathrm{MH}$} & Ecoli & 100 & 100 & 100 & 100 & 100 & 100 & 92.77 & 100 \\
\hline & Sau & 75.76 & 99.02 & 69.28 & 98.62 & 70.25 & 98.47 & 77.19 & 97.61 \\
\hline & Pae & 100 & 100 & 100 & 100 & 100 & 100 & 100 & 98.99 \\
\hline & Blank & 87.50 & 99.84 & 98.68 & 99.96 & 99.34 & 99.96 & 81.18 & 100 \\
\hline & Ecoli + Pae & 95.68 & 99.49 & 99.32 & 100 & 99.32 & 100 & 67.20 & 100 \\
\hline & Ecoli + Sau & 100 & 99.80 & 100 & 100 & 100 & 100 & 100 & 98.51 \\
\hline & $\mathrm{Pae}+\mathrm{Sau}$ & 90.78 & 99.96 & 100 & 99.96 & 100 & 99.96 & 100 & 98.81 \\
\hline \multirow{4}{*}{ MAC } & Ecoli & 94.23 & 100 & 100 & 100 & 100 & 100 & 100 & 99.53 \\
\hline & Pae & 96.03 & 99.73 & 100 & 100 & 100 & 100 & 100 & 98.46 \\
\hline & Blank & 88.89 & 99.18 & 99.36 & 99.92 & 99.36 & 99.96 & 100 & 96.81 \\
\hline & Ecoli + Pae & 100 & 100 & 100 & 100 & 100 & 100 & 100 & 99.96 \\
\hline
\end{tabular}




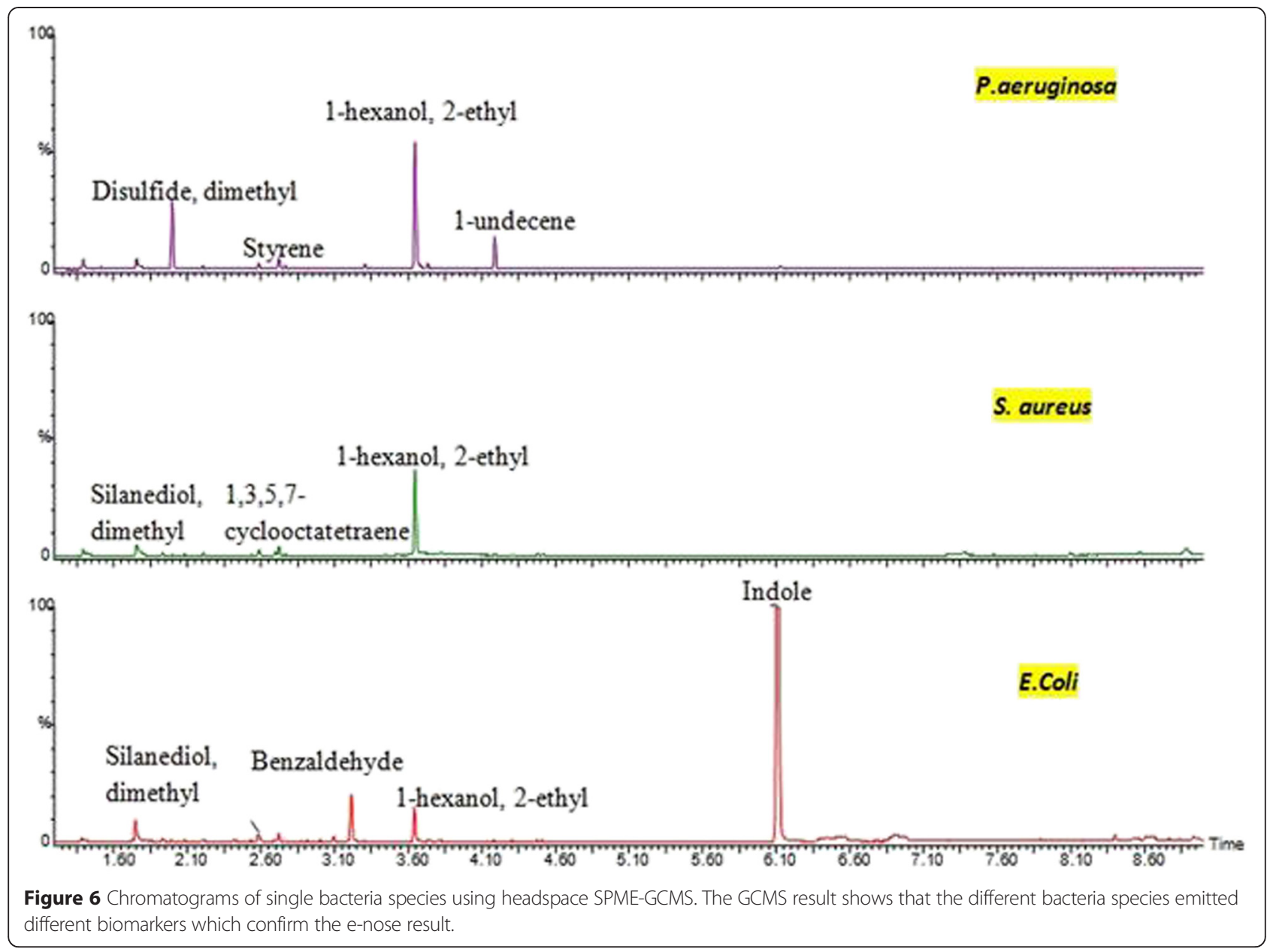

peaks are overlapped. Intensive data collections on poly microbial samples are required and must be subjected to chemometric technique. This to ensure correct biomarkers of poly microbial profile can be extracted from the TIC spectrogram.

\section{Discussion}

This paper proposed multi-class classification of single and poly microbial species in vitro to target diabetic foot infection. As mentioned previously in Figure 3, the wildtype bacteria obtained from debridement of diabetic foot wound produced almost similar VOCs with the standard ATCC bacteria. This proves that the wild bacteria species used in this experiment such as E. coli, S. aureus and $P$. aeruginosa have similar features with the standard ATCC bacteria as a reference. The e-nose was able to identify wild-type bacteria and match it with the standard bacteria samples.

Moreover, we preceded our investigations by analysing our data from a combination of the two groups of bacteria species in different media culture as shown in Figure 5. We found that the odour produced from single bacteria species was totally different with the odour produced by poly microbial species. This occurs because when two different gram-stain bacteria interact, they produce different volatile odours due to metabolic reactions to specific biochemical precursors and interactions among themselves while digesting nutrients [28].

The chromatograms from GC-MS allowed detailed analysis of potential biomarkers. Figure 6 shows an interesting result for three different bacteria species. E. coli emitted the highest peak of indole which showed similar results with other research studies $[44,51]$. Hence, the indole produced can be described as a common diagnostic biomarker for the identification of this bacterium.

It same goes with the TIC result for $P$. aeruginosa which consists of compounds undecene and methyl group (alkenes). Although, the highest peak was 1-hexanol-2-ethyl compound, 1-undecene and styrene can be concluded as a biomarker of $P$. aeruginosa since those compounds are only found in $P$. aeruginosa profile. This finding confirmed with studies of $[51,52]$.

Furthermore, the results TIC for S. aureus also showed that it contains alcohol group (silanediol), disulphide 


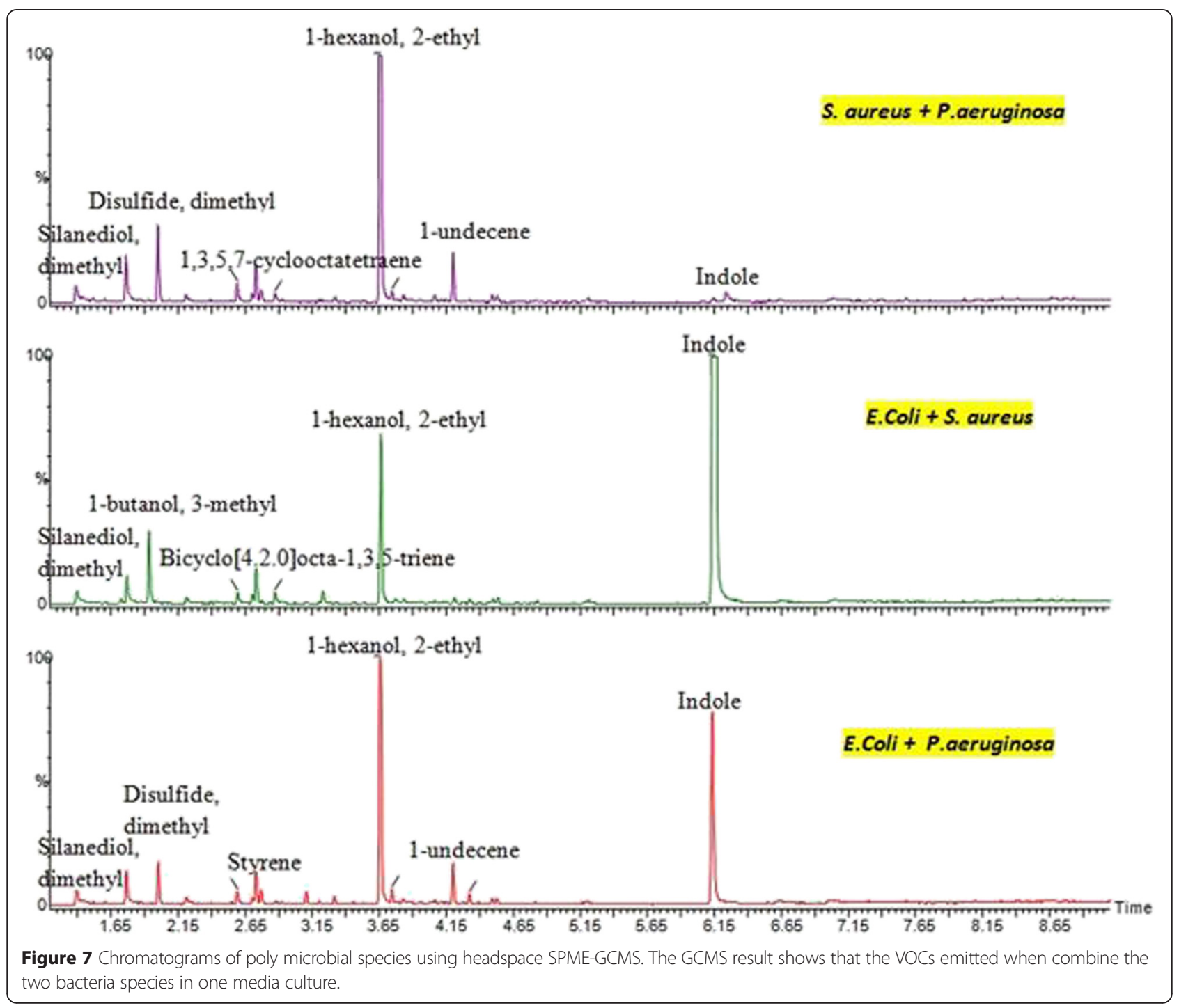

dimethyl, 1, 3, 5, 7-cyclooctatetraene and the highest peak was 1-hexanol-2-ethyl. Based on the VOC produced, 1, 3, 5,7 -cyclooctatetraene was the biomarker for that bacteria. These biomarker can be confirmed with other research such as $[44,52]$.

Unlike single bacteria groups, the combinations of mixed bacteria species as illustrated in Figure 7 create a unique smell print pattern for each bacterium. It consists of indole, methyl group and alcohol group such as hexanol and butanol. Those VOCs could be used as a volatile smell print of each bacterium. It has been observed that the biomarkers from the 'TIC peaks' for single bacteria species clearly showed the VOCs produced from that particular bacteria and can be extracted and used for classification. However, the GCMS result for poly microbial species are not conclusive since the bio-marker peaks are overlapped. Intensive data collections on poly microbial samples are required and later must be subjected to a chemometric technique which is not a straight forward analysis.

\section{Conclusions}

In conclusion, the analysis on the e-nose system was brought one stage closer to medical application as our study used real patient samples, rather than pure laboratory cultures, but a culture stage was still involved. The sampling procedure was carefully formulated to serve as proof of concept that will enable further work on in-vivo (direct sampling) of bacterial infection on diabetic foot ulcers.

\section{Competing interests}

The authors declare that they have no competing interests.

\section{Authors' contributions}

The research problem was defined by: MIO, AO and MSY. Designed the methods: AZ, NY and AAA. Design the algorithm and statistical analysis: MJM, AZ, NAR, and NZIZ. The experimental design was carried out by: NY, 
LMK and AYMS. Methods mostly implemented by NY with help from AO, MSY, AZ, MIO and AAA. Experiment and analysed the data: NY, AZ, MJM and NZIZ. NY wrote the paper with help from the other authors. All authors read and approved the final manuscript.

\section{Acknowledgements}

This work is supported by the Prototype Research Grant Scheme 9013-00015 by the Ministry of Education, Malaysia. The authors would like to thank Director of Hospital Tuanku Fauziah, Kangar, Perlis for their collaboration.

\section{Author details}

${ }^{1}$ Centre of Excellence for Advanced Sensor Technology, Universiti Malaysia Perlis, Perlis, Malaysia. ${ }^{2}$ Institute for Engineering Mathematics, Universiti Malaysia Perlis, Perlis, Malaysia. ${ }^{3}$ Nara Institute of Science and Technology, Takayama-cho, Ikoma-shi, Nara, Japan. ${ }^{4}$ Department of Microbiology|, Hospital Tuanku Fauziah, Jalan Kolam, Kangar, Perlis, Malaysia.

\section{Received: 12 August 2014 Accepted: 28 April 2015}

\section{Published online: 14 May 2015}

\section{References}

1. Bader MS. Diabetic foot infection. Am Fam Physician. 2008;78:71-9.

2. El-tahawy AT. Bacteriology of diabetic foot infections. Saudi Med J. 2000;21:344-7.

3. Roberts $A D$, Simon GL. Diabetic foot infections: the role of microbiology and antibiotic treatment. Semin Vasc Surg. 2012;25:75-81.

4. Raja NS. Microbiology of diabetic foot infections in a teaching hospital in Malaysia: a retrospective study of 194 cases. J Microbiol Immunol Infect. 2007:40:39-44

5. Cunha BA. Antibiotic selection for diabetic foot infections: a review. J Foot Ankle Surg. 2000;39:253-7.

6. Matsuura GT, Barg N. Update on the antimicrobial management of foot infections in patients with diabetes. Clin Diabetes. 2013;31:59-65.

7. Miller $\mathrm{AO}$, Henry M. Update in diagnosis and treatment of diabetic foot infections. Phys Med Rehabil Clin N Am. 2009;20:611-25.

8. Mettler J, Simcock M, Sendi P, Widmer AF, Bingisser R, Battegay M, et al. Empirical use of antibiotics and adjustment of empirical antibiotic therapies in a university hospital: a prospective observational study. BMC Infect Dis. 2007;7:1-10.

9. Islam S, Cawich SO, Budhooram S, Harnarayan P, Mahabir V, Ramsewak S, et al. Microbial profile of diabetic foot infections in Trinidad and Tobago. Prim Care Diabetes. 2013;7:303-8.

10. Cavanagh PR, Lipsky BA, Bradbury AW, Botek G. Treatment for diabetic foot ulcers. Lancet. 2005;366:1725-35.

11. Bozkurt F, Gulsun S, Tekin R, Hosoglu S, Acemoglu H. Comparison of microbiological results of deep tissue biopsy and superficial swab in diabetic foot infections. J Microbiol Infect Dis. 2011;1:122-7.

12. Al Benwan $\mathrm{K}, \mathrm{Al}$ Mulla A, Rotimi VO. A study of the microbiology of diabetic foot infections in a teaching hospital in Kuwait. J Infect Public Health. 2012:5:1-8.

13. Lipsky BA, Berendt AR, Cornia PB, Pile JC, Peters EJG, Armstrong DG, et al. Infectious diseases society of America clinical practice guideline for the diagnosis and treatment of diabetic foot infections. Clin Infect Dis. 2012;2012(54):132-73.

14. Nadeau JS, Wright BW, Synovec RE. Chemometric analysis of gas chromatography-mass spectrometry data using fast retention time alignment via a total ion current shift function. Talanta. 2010;81:120-8.

15. Pellati F, Prencipe FP, Benvenuti S. Headspace solid-phase microextractiongas chromatography-mass spectrometry characterization of propolis volatile compounds. J Pharm Biomed Anal. 2013;84:103-11.

16. Liu H, Wang H, Li C, Wang L, Pan Z, Wang L. Investigation of volatile organic metabolites in lung cancer pleural effusions by solid-phase microextraction and gas chromatography/mass spectrometry. J Chromatogr B Analyt Technol Biomed Life Sci. 2014;945-946:53-9.

17. Wilson AD, Baietto M. Applications and advances in electronic-nose technologies. 2009;9:5099-5148.

18. Casalinuovo IA, Di Pierro D, Coletta M, Di Francesco P. Application of electronic noses for disease diagnosis and food spoilage detection. Sensors. 2006;6:1428-39.

19. Dutta R, Hines EL, Gardner JW, Boilot P. Bacteria classification using Cyranose 320 electronic nose. Biomed Eng Online. 2002;1:4.
20. Dutta R, Das A, Stocks NG, Morgan D. Stochastic resonance-based electronic nose: a novel way to classify bacteria. Sensors Actuators B Chem. 2006;115:17-27.

21. Wilson AD. Future applications of electronic-nose technologies in healthcare and biomedicine. In: Akyar I, editor. Wide spectra qual control. July 2011. United States of America: InTech; 2011. p. 267-88.

22. Pavlou AK, Magan N, McNulty C, Jones J, Sharp D, Brown J, et al. Use of an electronic nose system for diagnoses of urinary tract infections. Biosens Bioelectron. 2002;17:893-9.

23. Chandiok S, Crawley BA, Oppenheim BA, Chadwick PR, Higgins S, Persaud KC. Screening for bacterial vaginosis: a novel application of artificial nose technology. J Clin Pathol. 1997;50:790-5.

24. Wilson AD, Baietto M. Advances in electronic-nose technologies developed for biomedical applications. Sensors (Bassel). 2011;11:1105-76.

25. Fend R, Kolk AHJ, Bessant C, Buijtels P, Klatser PR, Woodman AC. Prospects for clinical application of electronic-nose technology to early detection of Mycobacterium tuberculosis in culture and sputum. J Clin Microbiol. 2006:44:2039-45

26. Tiwari S, Pratyush DD, Dwivedi A, Gupta SK, Rai M, Singh SK. Microbiological and clinical characteristics of diabetic foot infections in northern India. J Infect Dev Ctries. 2012;6:2-5.

27. Hockstein NG, Thaler ER, Torigian D, Miller WT, Deffenderfer O, Hanson CW. Diagnosis of pneumonia with an electronic nose: correlation of vapor signature with chest computed tomography scan findings. Laryngoscope. 2004; 114:1701-5.

28. Pavlou AK, Magan N, Sharp D, Brown J, Barr H, Turner APF. An intelligent rapid odour recognition model in discrimination of Helicobacter pylori and other gastroesophageal isolates in vitro. Biosens Bioelectron. 2000;15:333-42.

29. Dragonieri S, Schot R, Mertens BJ A, Le Cessie S, Gauw SA, Spanevello A, et al. An electronic nose in the discrimination of patients with asthma and controls. J Allergy Clin Immunol. 2007;120:856-62.

30. Trincavelli M, Coradeschi S, Loutfi A, Söderquist B, Thunberg P. Direct identification of bacteria in blood culture samples using an electronic nose. IEEE Trans Biomed Eng. 2010;57:2884-90.

31. Tran VH, Chan HP, Thurston M, Jackson P, Lewis C, Yates D, et al. Breath analysis of lung cancer patients using an electronic nose detection system. IEEE Sens J. 2010;10:1514-8.

32. Gardner JW, Craven CD M, Hines EL. The prediction of bacteria type and culture growth phase by an electronic nose with a multi-layer perceptron network. Meas Sci Technol. 1998;9:120-7.

33. Weiner RD, Viselli SJ, Fulkert KA, Accetta P. Histology versus microbiology for accuracy in identification of osteomyelitis in the diabetic foot. J Foot Ankle Surg. 2011;50:197-200.

34. Abdullah AA, Yusuf N, Omar MI, Zakaria A, Kamarudin LM, Shakaff AY, et al. Multivariate prediction model for early detection and classification of bacterial species in diabetic foot ulcers. In Int Conf Adv Intell Syst Bioinformatics, Chem-Informatics, Bus Intell Soc Media Cybern. 2013;27-34.

35. Yusuf N, Omar Ml, Zakaria A, Abdullah AA, Kamarudin LM, Shakaff AYM, et al. Diagnosis of bacteria for diabetic foot infection using electronic nose technology. In 2013 IEEE Conf Wirel Sensors. 2013;118-122.

36. Abdullah AA, Yusuf N, Zakaria A, Omar Ml, Shakaff AY, Adom AH, et al. Bacteria classification using electronic nose for diabetic wound monitoring Appl Mech Mater. 2013;339:167-72

37. Azian Azamimi A, Tan Woei J, Chua Ai S, Nurlisa Y, Ammar Z, Mohammad labal O, et al. Rapid identification method of aerobic bacteria in diabetic foot ulcers using electronic nose. Adv Sci Lett. 2014;1:37-41.

38. Yusuf N, Abdullah AA, lqbal M, Zakaria A, Kamarudin LM, Md Shakaff AY, et al. Comparison of various pattern recognition techniques based on e-nose for identifying bacterial species in diabetic wound infections. WIT Trans Inf Commun Technol. 2014;53:43-59.

39. Yusuf N, Omar MI, Zakaria A, Jeffree Al, Thriumani R, Abdullah AA, et al. Evaluation of E-nose technology for detection of the causative bacteria in different culture media on diabetic foot infection. IEEE Conf Biomed Eng Sci. 2014;(December):1-4

40. Preti G, Thaler E, Hanson CW, Troy M, Eades J, Gelperin A. Volatile compounds characteristic of sinus-related bacteria and infected sinus mucus: analysis by solid-phase microextraction and gas chromatographymass spectrometry. J Chromatogr B Anal Technol Biomed Life Sci. 2009;877:2011-2018. 
41. Buszewski B, Ulanowska A, Ligor T, Jackowski M, Kłodzińska E, Szeliga J. Identification of volatile organic compounds secreted from cancer tissues and bacterial cultures. J Chromatogr B Analyt Technol sBiomed Life Sci. 2008;868:88-94.

42. Bunge M, Araghipour N, Mikoviny T, Dunkl J, Schnitzhofer R, Hansel A, et al. On-line monitoring of microbial volatile metabolites by proton transfer reaction-mass spectrometry. Appl Environ Microbiol. 2008;74:2179-86.

43. Allardyce RA, Langford VS, Hill AL, Murdoch DR. Detection of volatile metabolites produced by bacterial growth in blood culture media by selected ion flow tube mass spectrometry (SIFT-MS). J Microbiol Methods. 2006;65:361-5.

44. Zhu J, Bean HD, Kuo Y, Hill JE. Fast detection of volatile organic compounds from bacterial cultures by secondary electrospray ionization-mass spectrometry. J Clin Microbiol. 2010;48:4426-31.

45. Tait E, Perry JD, Stanforth SP, Dean JR. Use of volatile compounds as a diagnostic tool for the detection of pathogenic bacteria. TrAC, Trends Anal Chem. 2014;53:117-25.

46. Byun H, Persaud KC, Pisanelli AM. Wound-state monitoring for burn patients using E-nose/SPME system. ETRI J. 2010;32:440-6.

47. Vuckovic D, Zhang X, Cudjoe E, Pawliszyn J. Solid-phase microextraction in bioanalysis: New devices and directions. J Chromatogr A. 2010;1217:4041-60

48. Santos FJ, Galceran MT. Modern developments in gas chromatographymass spectrometry-based environmental analysis. J Chromatogr A. 2003;1000:125-51.

49. Dutta R, Gardner JW, Hines EL. Electronic noses diagnose illness: classification of ear, nose, and throat bacteria using a neural-network-based electronic nose. MRS Bull. 2004;(October):1-5.

50. Schiffman SS, Wyrick DW, Gutierrez-Osuna R, Nagle HT. Effectiveness of an electronic nose for monitoring bacterial and fungal growth. In: 7th Int Symp Olfaction Electron Nose. Brighton: UK; 2000:1-8.

51. Boots AW, Smolinska A, van Berkel JJBN, Fijten RRR, Stobberingh EE, Boumans MLL, et al. Identification of microorganisms based on headspace analysis of volatile organic compounds by gas chromatography-mass spectrometry. J Breath Res. 2014;8:1-12.

52. Sohrabi M, Zhang L, Zhang K, Ahmetagic A, Wei MQ. Volatile organic compounds as novel markers for the detection of bacterial infections. Clin Microbiol Open Access. 2014;03:1-6.

\section{Submit your next manuscript to BioMed Central and take full advantage of:}

- Convenient online submission

- Thorough peer review

- No space constraints or color figure charges

- Immediate publication on acceptance

- Inclusion in PubMed, CAS, Scopus and Google Scholar

- Research which is freely available for redistribution 